\title{
ANALYSIS OF PERFORATED WEB GIRDER LOAD BEARING CAPACITY
}

\author{
Aivars Vilguts ${ }^{1}$, Dmitrijs Serdjuks², Leonids Pakrastins ${ }^{3}$, Vadims Goremikins ${ }^{4}$ \\ 1,2,3,4 Institute of Structural Engineering and Reconstruction, Faculty of Civil Engineering, Riga Technical University, \\ Azenes Str. 16/20, LV-1048 Riga, Latvia \\ E-mail:1aivars.vilguts@gmail.com (correspondingauthor); ${ }^{2}$ dmitrijs@bf.rtu.lv; ${ }^{3}$ leonids.pakrastins@.rtu.lv; \\ 4goremikins@gmail.com
}

\begin{abstract}
A steel beam with perforated steel web is a type of flexural members, which is characterized by the decreased materials consumption. Existence of holes in the web enables to simplify placement of communications on the other hand. The using of beams with perforated web with hot-rolled double-T cross-section as a girder of transversal frame of trees hothouse is analysed in the paper. The beams are considered under the action of design vertical load, consisting from dead weight of the roof and snow load. The value of design vertical load is equal to $28 \mathrm{kN} / \mathrm{m}$. The grade of steel was S235. The dependence between diameters of holes, distances between holes, height of the beams cross-sections and materials consumption was obtained on the basis of numerical experiment. The numerical experiment was conducted for the simple beam with the span equal to $12 \mathrm{~m}$. The obtained dependence allows determining rational from the point of view of materials consumption diameters of holes, distances between holes and height of the beam, which were equal to $0.25 \mathrm{~m}, 1.03 \mathrm{~m}$ and $0.55 \mathrm{~m}$, correspondingly. The methodology for determination of coefficients of stress concentration was considered in the paper. The stress concentration factors were obtained by the FEM with the using of computer program ANSYS v14, the obtained results were also compared. It was stated that the difference does not exceed $2.34 \%$.
\end{abstract}

Keywords: steel framework, coefficients of stress concentration, material consumption, rational geometrical parameters

\section{Introduction}

Decrease of structural materials consumption is one of the most topical problems, which should be solved during the process of designing. There are a few ways how the problem should be fixed for the steel structures (Gogol 2009, Goremikins et al. 2010). Determination of geometrical parameters rational from the point of view of materials consumption enables to create structures, where materials are used with the maximum efficiency. This method is valid for all types of structures. Using of structures, where main load-bearing elements work at tension, is another way to decrease structural materials consumption (Goremikins 2013). Tensioned structures are rational in the cases of big spans, mainly. Preference should be made for the elements, working in bending, compression or compression with the bending in case of short spans. The beams and trusses are the main types of the girders, which can be used for the spans ranging from 6 and less till 42 and more meters. So, depending on the web structures, the girders can be divided into the following groups: girders with the solid web or beams, girders with the lattice web or trusses and beams with the perforated web. The beam with the perforated web took intermediate position between the beams and trusses. Perforation of the beam's web enables to decrease structural dead weight and simplify the placement of communications. However, holes in the web cause stress concentration.

So, determination of geometrical parameters of steel framework of hothouse with the span equal to $24 \mathrm{~m}$ rational from the point of view of material consumption is the main target of this study. Possibility to use a beam with the perforated web as one of the girder types must be considered. Investigations of coefficients of stress concentration must also be conducted.

\section{Structural solution of hothouse steel framework}

Steel framework for hothouse with the area of 3,042.7 $\mathrm{m}^{2}$, was considered. The hothouse consists of two sections which are intersected under direct angle (Fig. 1.). Hothouse steel framework is formed by the transversal and longitudinal frames. Steel of grade S235 is considered as a structural material for all load-bearing members of the framework.

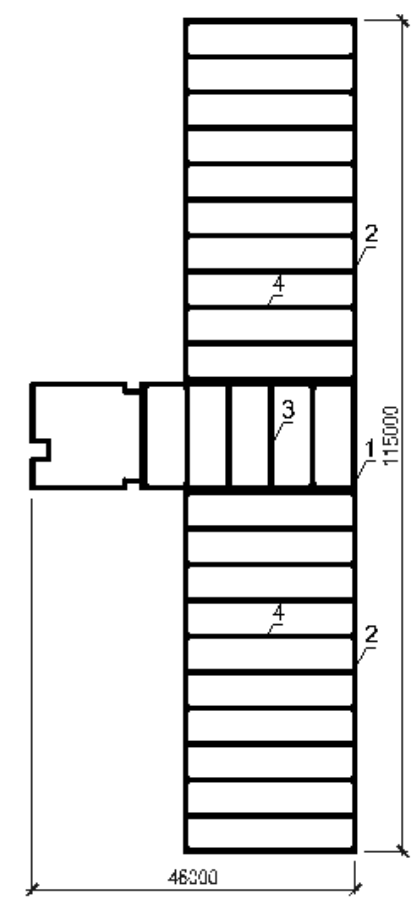

Fig. 1. Plane of hothouse steel framework: 1 - columns of transversal frames; 2 - columns of longitudinal frames; 3 - girders of transversal frames; 4 - girder of longitudinal frames. 
Longitudinal frame has one span equal to $11.5 \mathrm{~m}$ and girders pinned to column connections. Columns have hotrolled double-T cross-sections (EN 10025). Geometrical length of columns is equal to $6.2 \mathrm{~m}$ (Fig.2.).

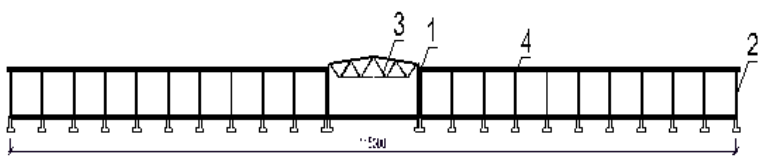

Fig. 2. Longitudinal cross-section of hothouse steel framework: designations as in Fig. 1.

Trapezium truss with rectangular web, two-slope top chord and rectangular hollow cross-sections (EN 10025) is a girder of longitudinal frame.

Transversal frame has two spans, which are equal to $12 \mathrm{~m}$ each, and girders pinned to column connections. Columns have hot-rolled double-T cross-sections (EN 10025). Geometrical length of columns is equal to $5.3 \mathrm{~m}$. The girders type for the transversal frame was chosen on the basis of comparison of variants. Four variants of transversal frames, which were distinguished by the girder types and number of spans, were considered. The variants were distinguished depending on the number of spans and type of girder web. The first and third variants have one span, equal to $24 \mathrm{~m}$. The second and fourth variants have two spans each, which are equal to $12 \mathrm{~m}$. The first and third variants have double-T crosssections with the solid web. First variant has welded double-T cross-sections, consisting from three steel sheets. The second and fourth variants have double$\mathrm{T}$ cross-sections with the perforated web. Transversal frame was considered under the action of dead weight, snow and wind loads. Design scheme of transversal frame is shown in Fig. 3.

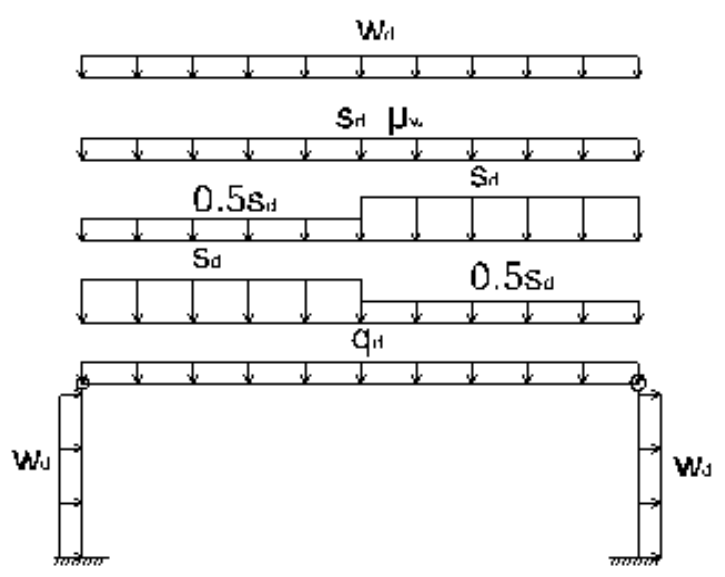

Fig. 3. Design scheme of transversal frame of hothouse steel framework: $\mathrm{q}_{\mathrm{d}}$ - design value of dead weight; $\mathrm{s}_{\mathrm{d}}-$ design value of snow load; $\mathrm{wd}_{\mathrm{d}}$ - design value of wind load.

Maximum value of vertical uniformly distributed load, acting on the girder, is equal to $28 \mathrm{kN} / \mathrm{m}$. All variants were analyzed by the algorithms, indicated in Eurocode 3 for members subjected to bending and compression with the bending (Davidson et al. 2003 Gardner et al. 2005). Check of lateral torsional buckling was not conducted, because stability of girders was provided by the roof structures. Number of holes was determined by the equations (1):

$n=\frac{L-2 \cdot l_{0}}{l_{1}}$,

where: $L-$ span of the beam; $l_{0}$ - distance from the edge of the hole till the girders edge; $l_{l}$ - distance between the centres of holes.

Material consumptions for the four above mentioned variants of transversal frames were evaluated as a sum of column and girder masses for the section of the building, consisting from 11 frames. The material consumptions were equal to $17.14,4.65,16.10$ and 4.49 tons for the first, second, third and fourth variants, correspondingly. Considering the obtained results allows making a conclusion that the number of spans is the main factor, affecting the materials consumption for the considered variants. Increase of the number of spans from one till two enables to decrease material consumption 3.69 and 3.59 times for both variants with and without perforation.

So, the fourth variant of transversal frame is the most rational from the point of view of materials consumption and it has been adopted for the hothouse steel framework. The geometrical parameters of the perforated girder rational from the point of view of materials consumption must be determined at the next stage of the work.

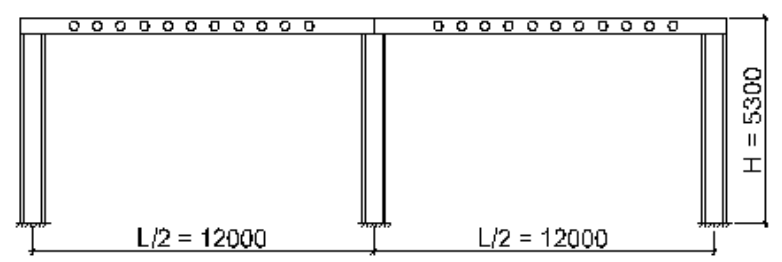

Fig. 4. Considered variant of transversal frame for hothouse steel framework.

\section{Analysis of Perforated Web Girder Load Bearing Capacity}

\section{Methodology of investigations}

Analysis of perforated web girder load bearing capacity was put forward as one of the main targets of this paper. The height of the girders cross-section (h), distance between the centres of the holes (a) and diameters of the holes $\left(\mathrm{d}_{0}\right)$ were considered as the main geometrical parameters of the perforated web girder (Fig. 5.).

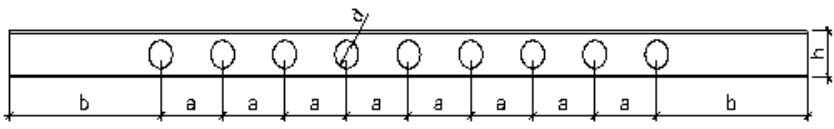

Fig. 5. Main geometrical parameters of the perforated web girder: height of the girder cross-section $(h)$; distance between the centers of the holes $(a)$; diameters of the holes $\left(d_{0}\right)$.

The dependences among load-bearing capacity of the perforated web girder, its materials consumption and main geometrical parameters were obtained. Each from the mentioned above main geometrical parameters has 
three values (maximum, minimum and mean). It means that the total number of the treated variants was equal to 27 (Eriksson et al. 2008). The dependences were obtained as a second degree polynomial equation on the basis of numerical experiment. The equation (2) illustrates the dependence of load-bearing capacity (q) on the height of the girder cross-section $(\mathrm{h})$, distance between the centres of the holes (a) and diameters of the holes $\left(\mathrm{d}_{0}\right)$.

$$
\begin{aligned}
& q=b_{0}+b_{1} \cdot h+b_{2} \cdot a+b_{3} \cdot d_{0}+ \\
& +b_{12} \cdot h \cdot a+b_{13} \cdot h \cdot d_{0}+b_{23} \cdot a \cdot d_{0}+ \\
& +b_{11} \cdot h^{2}+b_{22} \cdot a^{2}+b_{33} \cdot d_{0}{ }^{2} .
\end{aligned}
$$

The dependence between perforated web girder materials consumption and its main geometrical parameters has the similar form. Material consumption was determined as a relation of the total mass of the girders to the covered area.

The girder with perforated web was analyzed at the action of load combination, which involves dead weight, snow and wind (Fig. 3.). Design scheme of the girder is freely supported beam with the span, equal to $12 \mathrm{~m}$, loaded by the uniformly distributed load. Bending moments and shear forces acting in the load-bearing members were then used for determination of crosssections parameters. Dimensioning of the members crosssections was carried out by the Eurocode 3 . The girder with perforated web has hot-rolled IPE double-T crosssections.

The coefficients of dependences among load-bearing capacity of the perforated web girder, its materials consumption and main geometrical parameters were obtained by the less squares method. Rational from the point of view of load-bearing capacity values of height of the girders cross-section $(h)$, distance between the centers of the holes $(a)$ and diameters of the holes $\left(d_{0}\right)$ were determined by the system of equations (3).

$$
\left\{\begin{array}{l}
\frac{\partial q}{\partial h}=b_{1}+b_{12} \cdot a+b_{13} \cdot d_{0}+2 \cdot b_{11} \cdot h=0, \\
\frac{\partial q}{\partial a}=b_{2}+b_{12} \cdot h+b_{23} \cdot d_{0}+2 \cdot b_{22} \cdot a=0, \\
\frac{\partial q}{\partial d_{0}}=b_{3}+b_{13} \cdot h+b_{23} \cdot a+2 \cdot b_{33} \cdot d_{0}=0 .
\end{array}\right.
$$

The system of equations for determination of the main geometrical parameters of perforated web girder rational from the point of view of materials consumption has the similar form (Serdjuks et al. 2008). The obtained results were then corrected by the inspection.

\section{Characteristics of the perforated web girder and numerical results}

The height of the girder cross-section changes within the limits from 500 to $600 \mathrm{~mm}$. Hot-rolled double-T profiles IPE 500, IPE 550 and IPE 600 were considered. Distance between the centers of the holes $(a)$ and diameters of the holes $\left(d_{0}\right)$ changes within the limits from 1.0 till $2.0 \mathrm{~m}$ and from 0.2 till $0.4 \mathrm{~m}$, correspondingly.
Snow and wind loads were determined for Riga climatic conditions. Maximum intensities of the roof's dead weight, snow and wind loads are equal to 1.296 , 5.205 and $0.252 \mathrm{kPa}$, correspondingly. The roofing consists from the profiled steel sheets (RAN 153), heat insulation (PAROC ROS 30) and protective layers (ICOPAL).

The dependence between load-bearing capacity of the perforated web girder and its main geometrical parameters were obtained and shown in Fig. 6 and Fig. 7.

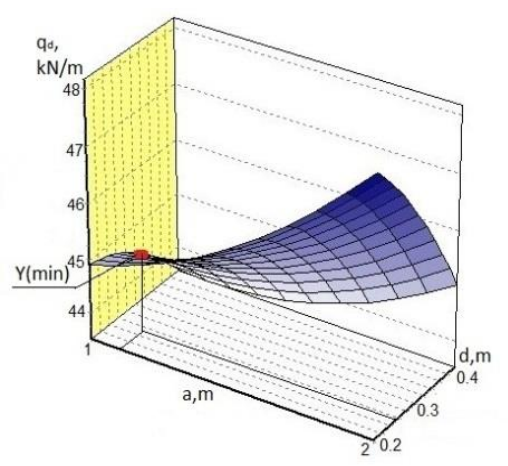

Fig. 6. Load-bearing capacity of the perforated web girder as a function from the distance between the centers of the holes $(a)$ and diameters of the holes $(d o)$. Height of the beams crosssection is equal to $0.55 \mathrm{~m}$

The dependence, which is shown in Fig. 6, was obtained for the constant height of the girders crosssection, which is equal to $0.55 \mathrm{~m}$. Load-bearing capacity of the perforated web girder changed within the limits from 44 to $47 \mathrm{kN} / \mathrm{m}$ in this case.

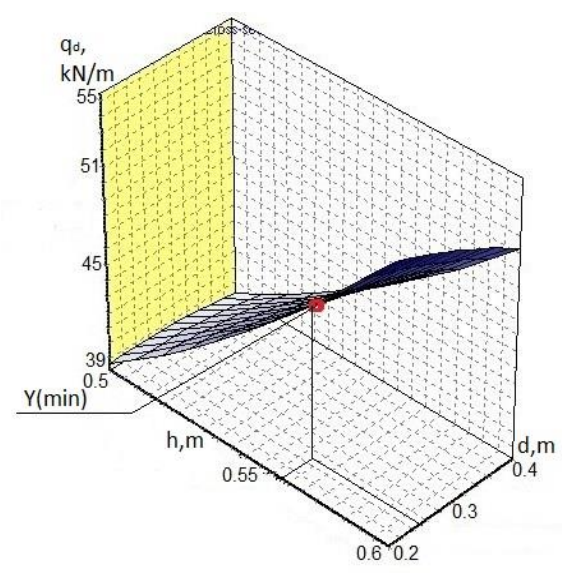

Fig. 7. Load-bearing capacity of the perforated web girder as a function from the girders height $(h)$ and diameters of the holes $\left(d_{0}\right)$. Distances between centers of the holes are equal to $1.00 \mathrm{~m}$

The dependence, which is shown in Fig. 7, was obtained for the constant distance between the centers of the holes, which is equal to $1.00 \mathrm{~m}$. Load-bearing capacity of perforated web girder changed within the limits from 37.40 to $53.72 \mathrm{kN} / \mathrm{m}$.

The coefficients of the second degree polynomial equations are given in Table 1 . 
Table 1. Coefficients of second degree polynomial equations

\begin{tabular}{l|l|l}
\hline $\begin{array}{l}\text { Coefficients of } \\
\text { second degree } \\
\text { polynomial } \\
\text { equations }\end{array}$ & $\begin{array}{l}\text { Dependence } \\
\text { between load- } \\
\text { bearing capacity of } \\
\text { the perforated web } \\
\text { girder and its main } \\
\text { geometrical } \\
\text { parameters }\end{array}$ & $\begin{array}{l}\text { Dependence } \\
\text { between materials } \\
\text { consumption of the } \\
\text { perforated web } \\
\text { girder and its main } \\
\text { geometrical } \\
\text { parameters }\end{array}$ \\
\hline b0 & 68.50 & 26.77 \\
b1 & -284.19 & -79.20 \\
b2 & -1.45 & 1.33 \\
b3 & 93.32 & -15.41 \\
b11 & 425.61 & 142.08 \\
b12 & 2.64 & -2.67 \\
b13 & -122.71 & 10.80 \\
b22 & 2.33 & -0.05 \\
b23 & -15.89 & 3.24 \\
b33 & -18.80 & -4.57 \\
\hline
\end{tabular}

The results, which were obtained for the perforated web girder, were compared with the same girder without perforation. It was stated that for the girders with the heights changing within the limits from 0.50 to $0.65 \mathrm{~m}$, load bearing capacity changes within the limits from 43.27 to $69.22 \mathrm{kN} / \mathrm{m}$. So, perforation causes load bearing capacity decrease from 5.71 to $28.16 \%$. Corresponding maximum dead weight decrease is equal to $7 \%$.

The dependence between materials consumption of the perforated web girder and its main geometrical parameters were obtained and shown in Fig. 8.

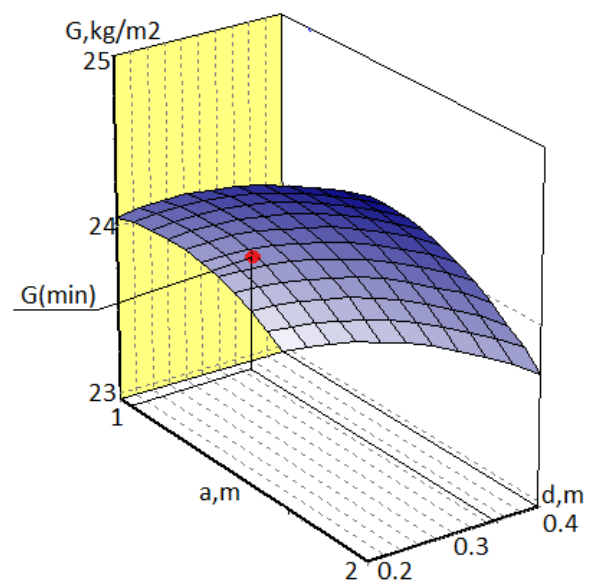

Fig. 8. Material consumption of the perforated web girder as a function from the distance between the centers of the holes $(a)$ and diameters of the holes $\left(d_{0}\right)$. Height of the beams crosssection is equal to $0.55 \mathrm{~m}$.

It is stated that material consumption changes within the limits from 19 to $29 \mathrm{~kg} / \mathrm{m} 2$.

The values of the obtained coefficients allow analyzing the level of importance of each from the three above mentioned main geometrical parameters of the perforated web girder. It can be stated that the height of the girder and diameters of the holes are the parameters which most significantly influence the total materials consumption.

Rational from the point of view of load bearing capacity values of height of the girders cross-section, distance between the centres of the holes and diameters of the holes were determined (see Table 2).

Table 2. Rational main geometrical parameters of the girder with the perforated web

\begin{tabular}{l|l|l}
\hline $\begin{array}{l}\text { Main geometrical } \\
\text { parameters of the girder } \\
\text { with the perforated web }\end{array}$ & $\begin{array}{l}\text { From the point } \\
\text { of view of load } \\
\text { bearing capacity }\end{array}$ & $\begin{array}{l}\text { From the } \\
\text { point of view } \\
\text { of material } \\
\text { consumption }\end{array}$ \\
\hline $\begin{array}{l}\text { Height of the girders } \\
\text { cross-section h, m }\end{array}$ & 0.55 & 0.51 \\
$\begin{array}{l}\text { Distance between } \\
\text { centers of the holes a, m }\end{array}$ & 1.03 & 1.02 \\
$\begin{array}{l}\text { Diameters of the holes } \\
\mathrm{d}_{0}, \mathrm{~m}\end{array}$ & 0.25 & 0.34 \\
\hline
\end{tabular}

So girder with the height of cross-section, distances between centres of the holes and diameters of the holes, equal to $0.55,1.00$ and $0.25 \mathrm{~m}$, correspondingly is considered as the rational solution. Corresponding load bearing capacity of the girder is equal to $44.5 \mathrm{kN} / \mathrm{m}$.

\section{Coefficient of stresses concentration}

The holes in the web of the girder cause concentration of stresses, which can be characterized by the coefficient of stress concentration $K_{t}$. The coefficient of stress concentration can be determined as a relation of maximum normal stresses, acting near the hole, to nominal normal stresses, acting in the section without perforation. The coefficient of stress concentration depends on the shape of the hole, its position and can change within the limits from 2 to 9 (Kadišs et al 1991, Vedennikov 1998).

The value of coefficient of stress concentration can be determined by the equation (4).

$$
K_{t}=\frac{\sigma_{\max }}{6 \cdot M / h_{w}^{2} \cdot d_{0}}
$$

where: $\sigma_{\max }-$ maximum normal stresses; $M$ - bending moment in considered section; $h_{w}$ - height of the girder's web; $d_{0}$ - diameters of the holes.

The dependence of coefficient of stress concentration on the height of girder and diameters of the holes was obtained (Fig. 9).

The values of coefficients of stress concentration change within the limits from 2.89 to 7.24 when the height of the girder and diameters of the holes change from 0.50 to 0.60 and from 0.20 to $0.40 \mathrm{~m}$, correspondingly. Distances between centres of the holes are equal to $1.00 \mathrm{~m}$. 


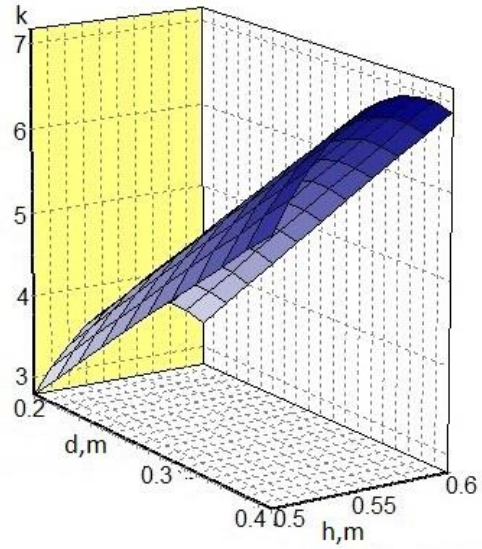

Fig. 9. Coefficient of stress concentration as a function from the girders height and diameters of the holes ( $\left.\mathrm{d}_{0}\right)$. Distances between centres of the holes are equal to $1.00 \mathrm{~m}$.

The obtained results were checked using the software ANSYS. The girder with the height and diameters of the holes equal to 0.55 and $0.40 \mathrm{~m}$ was modelled by the finite element Shell (Elastic 4node 63). The obtained results are shown in Figure 10.

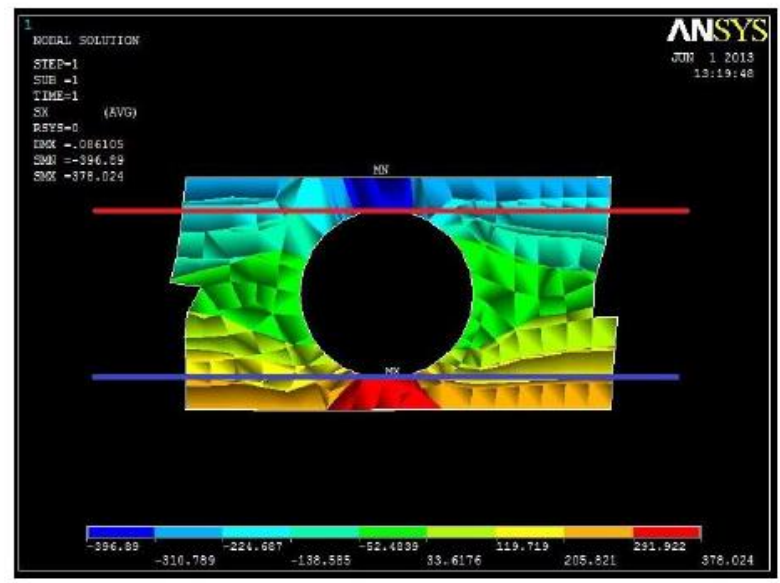

Fig. 10. Stress distribution in the perforated web girder.

The values of coefficients of stress concentration were then determined by the formula (5) (Kadišs et al 1991).

$$
K_{t}=\frac{\sigma_{\max }}{\sigma}
$$

where: $\sigma_{\max }-$ maximum normal stresses; $\sigma$ - nominal normal stresses, acting in the section without perforation.

The values of maximum normal stresses and nominal normal stresses were equal to 396 and $56 \mathrm{MPa}$, correspondingly for the section, which is placed in the middle of the span. So, the value of coefficients of stress concentration was equal to 7 . The difference between the results, obtained by the formula (4) and by the software ANSYS, was equal to $2.34 \%$. So, the results obtained by the equations (4) can be considered as adequate.

\section{Conclusions}

Load-bearing capacity of the girder with the span equal to $12 \mathrm{~m}$ with the perforated web was analyzed. The dependences among load-bearing capacity of the perforated web girder, its materials consumption and height of the girders cross-section, distance between the centers of the holes and diameters of the holes were obtained. It was shown that when the height of the girders cross-section changes within the limits from 0.50 to $0.60 \mathrm{~m}$, the distance between centres of the holes and diameters of the holes change within the limits from 1.0 till $2.0 \mathrm{~m}$ and from 0.2 till $0.4 \mathrm{~m}$, correspondingly, load bearing capacity of the girder changes within the limits from 37.40 to $69.22 \mathrm{kN} / \mathrm{m}$. Corresponding materials consumption changes from 19.09 to $29.01 \mathrm{~kg} / \mathrm{m}^{2}$.

The girder with the height of cross-section, distances between centres of the holes and diameters of the holes, equal to $0.55,1.00$ and $0.25 \mathrm{~m}$, correspondingly, is considered as a rational one. Corresponding load bearing capacity of the girder is equal to $44.5 \mathrm{kN} / \mathrm{m}$.

The dependence of the coefficient of stress concentration on the height of girder and diameters of the holes was obtained. The values of coefficients of stress concentration change within the limits from 2.89 to 7.24 when the height of the girder and diameters of the holes change from 0.50 to 0.60 and from 0.20 to $0.40 \mathrm{~m}$, correspondingly. Distances between centres of the holes are equal to $1.00 \mathrm{~m}$.

\section{References}

Davison, B.; Owens, W., 2003. Steel Designers' Manual. 6 th Edition. Blackwell publishing. $1370 \mathrm{p}$.

Eriksson, L.; Johansson, E.; Kettaneh-Wold, N.; Wikstrom, C.; Wold, S., 2008. Design of Experiments. Principles and Applications. Umetrics AB, $459 \mathrm{p}$.

Gogol, M., 2009. Shaping of Effective Steel Structures. Scientific Proceedings of Rzeszow Technical University, 264, pp. 43-56.

Gardner, L.; Nethercot, D. A., 2005. Designers' Guide to Eurocode 3: Design of Steel Structures. Thomas Thelford Ltd., $165 \mathrm{p}$

Goremikins, V., 2013. Rational Large Span Prestressed Cable Structure. Doctoral Thesis. Riga: RTU. 155 p.

Goremikins, V.; Rocens, K.; Serdjuks, D., 2010. Evaluation of Rational Parameters of Trussed Beam. Scientific Journal of Riga Technical University, 11(2), pp. 21-25.

Kadišs, F.; Roze, A.; Sabulis, P., 1991. Metāla konstrukcijas. Rīga. Zvaizgne. 416 p.

Serdjuks, D.; Rocens, K., 2004. Decrease the Displacements of a Composite Saddle-Shaped Cable Roof. Mechanics of Composite Materials, 40(5), pp.675-684. Available at: http://dx.doi.org/10.1023/B:MOCM.0000047234.72813.2e

Vedenikov, G., 1998. Metaliceskije konstrukciji. Obshij kurs. Moskva: Strojizdat. 760 p. 